\title{
Correction to: Landmark-guided versus modified ultrasound-assisted Paramedian techniques in combined spinal-epidural anesthesia for elderly patients with hip fractures: a randomized controlled trial
}

\author{
Bo Qu', Luying Chen'1, Yuling Zhang ${ }^{1}$, Mengting Jiang ${ }^{1}$, Caineng $\mathrm{Wu}^{2}$, Wuhua $\mathrm{Ma}^{2}$ and Yuhui $\mathrm{Li}^{2^{*}}$
}

Correction to: BMC Anesthesiol 20, 248 (2020)

https://doi.org/10.1186/s12871-020-01172-x

Following publication of the original article [1], the authors reported two errors one in the Abstract section and one in the Result section.

In the Abstract section, the sentence "The median number of attempts was lower in ultrasound-assisted group (1 [1]) than landmark-guided group $(2[1,2]), P<0.001)$ " It should be corrected to "The median number of attempts was lower in ultrasound-assisted group $(1[1,1])$ than landmark-guided group (2 [1, 2]), P < 0.001)."

In the Result section, paragraph 7 , the sentence "(Table 5) A subgroup analysis was conducted for 12 patients with scoliosis (Table 6)." should be corrected to "A subgroup analysis was conducted for 12 patients with scoliosis (Table 6)."

The original article has been updated.

\section{Author details}

'Guangzhou University of Chinese Medicine, Guangzhou 510405,

Guangdong, China. ${ }^{2}$ Department of Anesthesiology, The First Affiliated Hospital of Guangzhou University of Chinese Medicine, Guangzhou 510405,

Guangdong, China.
Published online: 23 October 2020

\section{Reference}

1. Qu B, Chen L, Zhang Y, et al. Landmark-guided versus modified ultrasoundassisted Paramedian techniques in combined spinal-epidural anesthesia for elderly patients with hip fractures: a randomized controlled trial. BMC Anesthesiol. 2020;20:248. https://doi.org/10.1186/s12871-020-01172-x.

The original article can be found online at https://doi.org/10.1186/s12871020-01172-x

*Correspondence: liliuyuhui@126.com; liyuhui1531@gzucm.edu.cn

${ }^{2}$ Department of Anesthesiology, The First Affiliated Hospital of Guangzhou

University of Chinese Medicine, Guangzhou 510405, Guangdong, China

(c) The Author(s). 2020 Open Access This article is licensed under a Creative Commons Attribution 4.0 International License, which permits use, sharing, adaptation, distribution and reproduction in any medium or format, as long as you give appropriate credit to the original author(s) and the source, provide a link to the Creative Commons licence, and indicate if changes were made. The images or other third party material in this article are included in the article's Creative Commons licence, unless indicated otherwise in a credit line to the material. If material is not included in the article's Creative Commons licence and your intended use is not permitted by statutory regulation or exceeds the permitted use, you will need to obtain permission directly from the copyright holder. To view a copy of this licence, visit http://creativecommons.org/licenses/by/4.0/ The Creative Commons Public Domain Dedication waiver (http://creativecommons.org/publicdomain/zero/1.0/) applies to the data made available in this article, unless otherwise stated in a credit line to the data. 